\title{
TRAVEL TIMES OF PRINCIPAL P AND S PHASES OVER SMALL DISTANCES IN SOUTHERN CALIFORNIA*
}

\author{
By B. Gutenberg
}

\section{INTRODUCTION}

MoRe THAN ten years ago the author published (Gutenberg, 1932) average traveltime curves for near-by shocks in southern California, ${ }^{1}$ based on records of twentyone shocks. Since then, additional shocks suitable for study have accumulated. From these, fifty shocks have been selected and studied in detail. Arrival times of all

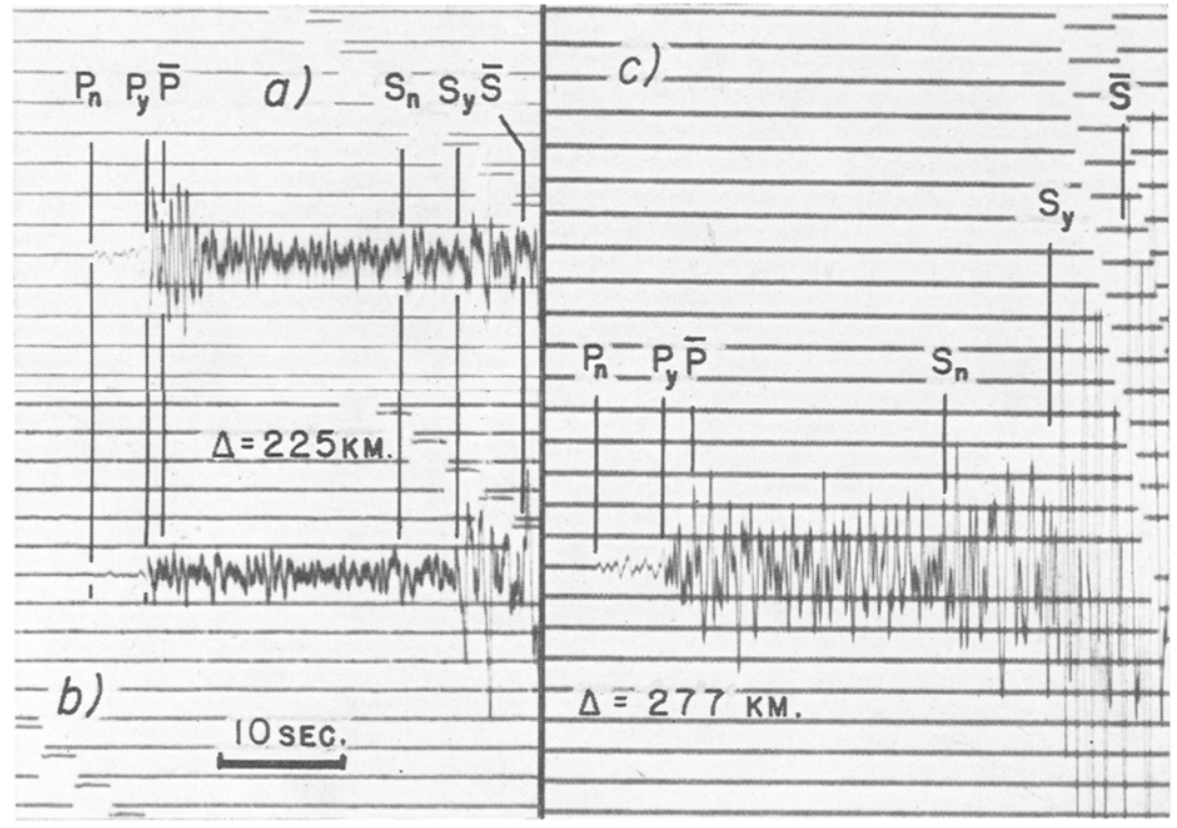

Fig. 1. Seismograms recorded by standard Wood-Anderson torsion seismographs. $a$ and $b$, shock no. 8, about $25 \mathrm{~km}$. southeast of Haiwee, recorded at Riverside; $a, \mathrm{~N}-\mathrm{S}, b, \mathrm{E}-\mathrm{W}$ component. Epicenter north of station (azimuth about $355^{\circ}$ ). Note relatively large $\mathrm{P}$ waves on $a, \mathrm{Sy}$ and $\overrightarrow{\mathrm{S}}$ waves on $b$, which are to be discussed in a paper now in preparation. $c$, shock no. 32, Elsinore region, recorded at Haiwee, $\mathrm{E}-\mathrm{W}$ component.

clearly marked phases were read repeatedly from originals as well as from enlarged copies, in which approximately $2 \mathrm{~mm}$. correspond to 1 sec. Then each shock was studied separately.

The material used, the location of the epicenters, the depths of foci, the magnitudes of the shocks, and the accuracy in reading times of arrival have already been published (Gutenberg, 1943a). Table 1 gives a summary of these results. A map showing the location of the stations and epicenters, and data about the stations, are to be found in the earlier paper (Gutenberg, 1943a).

* Manuscript received for publication April 12, 1943.

1 By agreement with Dr. P. Byerly, the area investigated at Pasadena and called "southern California" in papers published from the Seismological Laboratory includes Mono, Inyo, Tulare, Kings, and San Luis Obispo counties and all California counties to the south. 
TABLE 1

DATA FOR ShOCKS

\begin{tabular}{|c|c|c|c|c|c|c|c|c|c|c|}
\hline \multirow{2}{*}{$\begin{array}{r}\text { No. } \\
1 \\
1\end{array}$} & \multicolumn{2}{|l|}{ Date } & \multirow{2}{*}{$\frac{\text { Origin time }}{\text { hr. min. sec. }}$} & \multicolumn{2}{|c|}{ Longitude } & \multicolumn{2}{|c|}{ Latitude } & \multirow{2}{*}{ Magnitude } & \multirow{2}{*}{$\frac{\begin{array}{c}\text { No. of } \\
\text { stations }\end{array}}{13}$} & \multirow{2}{*}{ 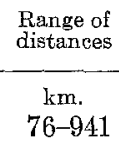 } \\
\hline & 1940, July & 8 & & $\begin{array}{l}\text { deg. } \\
118\end{array}$ & $\begin{array}{c}\min . \\
48\end{array}$ & $\begin{array}{c}\text { deg. } \\
37\end{array}$ & $\frac{\min .}{37}$ & & & \\
\hline 2 & 1940, July & 22 & $15: 00: 32.9$ & 118 & 46 & 37 & 38 & 4.6 & 12 & $75-940$ \\
\hline 3 & 1938, Dee. & 3 & $09: 42: 50.2$ & 118 & 40 & 37 & 32 & 5.5 & 14 & $61-926$ \\
\hline 4 & 1941, Sept. & 14 & $08: 43: 31.8$ & 118 & 44 & 37 & 34 & 5.8 & 16 & $67-932$ \\
\hline 5 & 1941, Sept. & 14 & $10: 21: 18.7$ & 118 & 44 & 37 & 34 & 5.5 & 16 & $67-932$ \\
\hline 6 & 1941, Sept. & 14 & $10: 39: 11.9$ & 118 & 44 & 37 & 34 & 6.0 & 16 & $67-932$ \\
\hline 7 & 1941, Dec. & 30 & $22: 48: 44.0$ & 118 & 44 & 37 & 34 & 5.4 & 16 & $67-932$ \\
\hline 8 & 1939, Jan. & 7 & $12: 21: 491 / 4$ & 117 & 45 & 36 & 00 & 5.0 & 13 & $25-762$ \\
\hline 9 & 1938, Sept. & 17 & $06: 23: 04.7$ & 117 & 41 & 35 & 39 & 4.8 & 14 & $59-738$ \\
\hline 10 & 1939, May & 4 & $12: 44: 46^{3} / 4$ & 114 & 49 & 35 & 58 & 5.0 & 9 & $2-552$ \\
\hline 11 & 1938, Aug. & 17 & $23: 39: 441 / 4$ & 116 & 13 & 34 & 52 & 4.5 & 9 & $143-576$ \\
\hline 12 & 1939, Mar. & 22 & $11: 16: 361 / 2$ & 116 & 08 & 34 & 42 & 3.8 & 9 & $139-570$ \\
\hline 13 & 1939, Feb. & 23 & $00: 45: 50.6$ & 119 & 01 & 34 & 52 & 4.6 & 13 & $80-814$ \\
\hline 14 & 1939, Feb. & 23 & $01: 18: 45.7$ & 119 & 00 & 34 & 54 & 4.8 & 13 & $83-813$ \\
\hline 15 & 1939, May & 7 & $18: 48: 03.7$ & 119 & 03 & 34 & 54 & 4.4 & 12 & $79-818$ \\
\hline 16 & 1941, Sept. & 21 & $11: 53: 07.2$ & 118 & 56 & 34 & 52 & 5,2 & 16 & $86-806$ \\
\hline 17 & 1941, June & 30 & $23: 50: 54.8$ & 119 & 35 & 34 & 22 & 5.9 & 18 & $14-849$ \\
\hline 18 & 1935, July & 13 & $02: 54: 16.5$ & 117 & 54 & 34 & 12 & 4.7 & 11 & $15-693$ \\
\hline 19 & 1941, Jan. & 29 & $17: 34: 46.9$ & 118 & 03 & 33 & 58 & 4.1 & 7 & $23-348$ \\
\hline 20 & 1940 , Oct. & 10 & $21: 57: 12.3$ & 118 & 27 & 33 & 46 & 4.7 & 11 & $49-731$ \\
\hline 21 & 1938, Aug. & 30 & $19: 18: 12.0$ & 118 & 16 & 33 & 44 & 4.4 & 9 & $47-714$ \\
\hline 22 & 1941, Nov. & 14 & $00: 41: 36.3$ & 118 & 15 & 33 & 47 & 5.4 & 13 & $41-714$ \\
\hline 23 & 1941, Oct. & 21 & $22: 57: 18.5$ & 118 & 13 & 33 & 49 & 4.9 & 11 & $37-711$ \\
\hline 24 & 1941, Oct. & 22 & $02: 32: 213 / 4$ & 118 & 13 & 33 & 52 & 3.8 . & 8 & $31-370$ \\
\hline 25 & 1939, Dec. & 27 & $11: 28: 49.0$ & 118 & 12 & 33 & 47 & 4.7 & 10 & $41-709$ \\
\hline 26 & 1933, Oct. & 2 & $01: 10: 17.6$ & 118 & 08 & 33 & 47 & 5.4 & 12 & $41-696$ \\
\hline 27 & 1933, Mar. & 10 & $17: 54: 07.8$ & 117 & 58 & 33 & 37 & 6.3 & 12 & $62-684$ \\
\hline 28 & 1940, Apr. & 18 & $10: 43: 43.9$ & 117 & 21 & 34 & 02 & 4.4 & 11 & $5-640$ \\
\hline 29 & 1939, Nov. & 7 & $10: 52: 08.4$ & 117 & 17 & 34 & 00 & 4.7 & 8 & $9-633$ \\
\hline 30 & 1940, Feb. & 19 & $04: 06: 55.7$ & 117 & 03 & 34 & 01 & 4.6 & 11 & $30-612$ \\
\hline 31 & 1935, Oct. & 24 & $06: 48: 07.6$ & 116 & 48 & 34 & 06 & 5.1 & 7 & $54-358$ \\
\hline 32 & 1938, May & 31 & $00: 33: 54.0$ & 117 & 32 & 33 & 40 & 5.3 & 12 & $39-646$ \\
\hline 33 & 1938, July & 5 & $10: 06: 54.6$ & 117 & 35 & 33 & 40 & 4.4 & 10 & $40-650$ \\
\hline 34 & 1938, Aug. & 6 & $14: 00: 55.0$ & 117 & 34 & 33 & 42 & 3.8 & 9 & $36-650$ \\
\hline 35 & 1940, Feb. & 25 & $13: 23: 47.1$ & 117 & 32 & 33 & 41 & 3.4 & 5 & $37-94$ \\
\hline 36 & 1940, May & 17 & $21: 03: 58.5$ & 116 & 18 & 34 & 05 & 5.4 & 14 & $96-682$ \\
\hline 37 & 1940, May & 17 & $21: 51: 201 / 4$ & 116 & 20 & 34 & 04 & 5.2 & 13 & $97-680$ \\
\hline 38 & 1940, May & 17 & $22: 04: 30.6$ & 116 & 19 & 34 & 04 & 4.6 & 13 & $98-682$ \\
\hline 39 & 1940, May & 17 & $23: 21: 32.7$ & 116 & 20 & 34 & 04 & 5.0 & 13 & $97-680$ \\
\hline 40 & 1940, May & 31 & $21: 27: 01.2$ & 116 & 20 & 34 & 05 & 4.7 & 10 & $95-552$ \\
\hline 41 & 1940, May & 31 & $22: 54: 28.0$ & 116 & 20 & 34 & 06 & 4.3 & 9 & $97-552$ \\
\hline 42 & 1940, June & 1 & $22: 13: 10.2$ & 116 & 20 & 34 & 05 & 4.5 & 10 & $95-551$ \\
\hline 43 & 1940, June & 6 & $14: 21: 15.1$ & 116 & 19 & 34 & 00 & 4.3 & 10 & $88-547$ \\
\hline 44 & 1940, June & 6 & $15: 56: 371 / 4$ & 116 & 22 & 34 & 01 & 4.4 & 10 & $87-552$ \\
\hline 45 & 1940, June & 11 & $11: 51: 18.1$ & 116 & 19 & 34 & 02 & 4.4 & 10 & $91-549$ \\
\hline 46 & 1937, Mar. & 25 & $08: 49: 03.0$ & 116 & 28 & 33 & 28 & 6.0 & 8 & $99-544$ \\
\hline 47 & 1939, May & 12 & $11: 25: 021 / 4$ & 116 & 26 & 33 & 28 & 4.5 & 9 & $101-541$ \\
\hline 48 & 1940, June & 4 & 02:35:08.3 & 116 & 26 & 33 & 00 & 5.1 & 10 & $55-532$ \\
\hline 49 & 1940 , July & 21 & $00: 36: 03.0$ & 115 & 59 & 33 & 10 & 4.4 & 10 & $83-493$ \\
\hline 50 & 1940, May & 18 & $20: 36: 40.9$ & 115 & 30 & 32 & 44 & 6.7 & 15 & $144-844$ \\
\hline
\end{tabular}


Three seismograms with the six principal phases are reproduced in figure 1. Beginnings of other seismograms selected from those used in the present paper, and showing $\mathrm{P}$ phases only, have been published in another paper (Gutenberg, 1943b, pl. 1. Note that on this plate the phase "Py" of the present paper is marked "P*.")

The present paper contains a study of travel-time curves for $\bar{P}, \mathrm{Py}, \mathrm{Pn}, \overline{\mathrm{s}}, \mathrm{Sy}$, and $\mathrm{Sn}$ in southern California, based on seismograms of the fifty shocks listed in table 1 .

\section{Traves TIMes of $\overline{\mathrm{P}}$}

In the investigation of travel times of $\overline{\mathrm{P}}$ it must be considered that the observed times of arrival as a function of epicentral distance $\Delta$ do not lie along a straight line, because of the effect of the focal depth $h$. To avoid such a curvature, either the hypocentral distance $D$ must be used, where $D^{2}=\Delta^{2}+h^{2}$ which leads to $t=D / V$ ( $V=$ velocity); or the quantity $(D-\Delta) / V$ must be subtracted from the observed travel times before they are used. This procedure means the reduction of the observed times to those which would result for a focal depth zero. For either procedure the focal depth $h$ must be known. For $h=18 \mathrm{~km}$., which seems to be a good approximation for all shocks listed in table 1, the corrections to be subtracted from the observed times to find the travel times for focal depth zero are given in table 2 , supposing that the waves travel only in the average granitic layer.

TABLE 2

Delay of $\overline{\mathrm{P}}$ Due to a Focai Depth of $18 \mathrm{Km}$.

\begin{tabular}{lcccccccccc}
\hline Distance & 0 & 10 & 20 & 30 & 40 & 60 & 80 & 100 & 150 & 200 \\
Delay & 3.2 & 1.9 & 1.2 & 0.9 & 0.7 & 0.5 & 0.4 & 0.3 & 0.2 & 0.1 \\
\hline
\end{tabular}

In addition, the observed times must be corrected for elevation $z$ of the station. This correction $\tau$ is given by

$$
\tau=-z \cos i_{0} / V_{0}=-z \sqrt{\left(1 / V_{0}\right)^{2}-\left(1 / V_{n}\right)^{2}} .
$$

where $i_{0}=$ angle of incidence, $V_{0}=$ velocity at the station, and $V_{n}=$ velocity at the point where the ray is horizontal. Usually, the sedimentary layers are not thick enough to affect the angle of incidence significantly, and $V_{0}$ may be taken as 5.57. As the path of $\overline{\mathrm{P}}$ in general has no point with a horizontal tangent, the second form of equation (1) cannot be used. The first form of the equation gives approximately the following corrections $\tau$, to be subtracted from the observed travel times of $\overline{\mathrm{P}}$ for each $\mathrm{km}$. in elevation $z$ of the station at the epicentral distance $\Delta$ :

$\begin{array}{cccccc}\Delta & 0 & 20 & 50 & 100 & 300 \mathrm{~km} . \\ \tau / z & 0.18 & 0.15 & 0.07 & 0.04 & 0.02 \mathrm{sec} .\end{array}$

These corrections are usually less than 0.1 sec., and are to be considered only for Tinemaha $(z=1.2 \mathrm{~km}$.), Haiwee $(1.1 \mathrm{~km}$.), Mount Wilson $(1.7 \mathrm{~km}$.), and Palomar $(1.7 \mathrm{~km}$.) in shocks near these stations.

At Santa Barbara a systematic delay of 0.1 to 0.2 sec. seems to exist in all phases. This is possibly an effect of the thick underlying sediments. 
In determining the epicenters it has been assumed that the velocities of the various longitudinal phases used are the same everywhere in southern California. This same assumption must be made if the velocity of a given phase is investigated by using a single shock; therefore no additional assumption is introduced if shocks originating in a given small area are combined in the investigation. Errors in origin time for the different shocks of one such group are affected mainly by errors in the velocity, and hence the use of several shocks of the same region in general will improve the resulting values of both origin time and velocity.

\section{TABLE 3}

Velocity $V$ (Km/sec.) of $\overline{\mathrm{P}}$, Its Standard Errors, Standard Errors of the Origin Time $O$ (in Seconds), and Number $n$ OF Odservations Used for Various

REgIONS IN SOUTHERN CALIForNIA

(For identifieation numbers of shocks see table 1. $\Delta=$ epicentral distance in $\mathrm{km}$. )

\begin{tabular}{|c|c|c|c|c|c|c|c|c|}
\hline \multirow{2}{*}{$\begin{array}{l}\text { Shock } \\
\text { no. }\end{array}$} & \multirow{2}{*}{$n$} & \multirow{2}{*}{ Range of $\Delta$} & \multirow{2}{*}{$V$} & \multicolumn{2}{|c|}{ Standard error } & \multicolumn{3}{|c|}{ Revised values of } \\
\hline & & & & $V$ & 0 & $V$ & $\begin{array}{l}\text { Standard } \\
\text { error }\end{array}$ & $n$ \\
\hline 1 to 7 & 53 & 67 to 415 & 5.60 & 0.02 & 0.2 & 5.584 & 0.006 & 46 \\
\hline 8,9 & 13 & 25 to 401 & 5.57 & 0.05 & 0.3 & 5.579 & 0.019 & 10 \\
\hline 10 to 12 & 14 & 140 to 411 & 5.54 & 0.04 & 0.4 & 5.574 & 0.019 & 14 \\
\hline 13 to 16 & 23 & 80 to 278 & 5.60 & 0.03 & 0.2 & 5.578 & 0.015 & 26 \\
\hline 17 & 10 & 133 to 473 & 5.57 & 0.04 & 0.4 & 5.571 & 0.044 & 10 \\
\hline 18,19 & 12 & 23 to 348 & 5.55 & 0.02 & 0.2 & 5.569 & 0.038 & 7 \\
\hline 20 to 27 & 46 & 41 to 714 & 5.57 & 0.01 & 0.1 & 5.575 & 0.009 & 44 \\
\hline 28 to 31 & 27 & 30 to 394 & 5.58 & 0.02 & 0.2 & 5.590 & 0.016 & 24 \\
\hline 32 to 35 & 22 & 27 to $401 ; 646^{\mathrm{a}}$ & 5.53 & 0.01 & 0.1 & 5.570 & 0.013 & 18 \\
\hline 36 to 45 & 50 & 91 to $379 ; 549$ a & 5.56 & 0.02 & 0.1 & 5.578 & 0.008 & 49 \\
\hline 46,47 & 11 & 99 to 326 & 5.65 & 0.03 & 0.2 & 5.557 & 0.017 & 11 \\
\hline 48,49 & 11 & 55 to 484 & 5.62 & 0.02 & 0.2 & 5.578 & 0.008 & 9 \\
\hline 50 & 9 & 165 to 839 & 5.60 & 0.03 & 0.4 & 5.577 & 0.019 & 9 \\
\hline
\end{tabular}

a Observation at Tueson in shoeks 32 and 36 , respectively.

In the first calculation the method of least squares was applied to all data for each group, with the origin time and the velocity of $\overline{\mathrm{P}}$ as unknown quantities. Shock 20 was omitted as too far west, and shock 24 as too small. In the revision both were included. In table $3, n$ is the number of separate instances used. In columns 5 and 6 the "standard" (or "mean") errors for the velocity $V$ and the origin time $O$ of the various groups are given. The "probable" errors may be found through multiplication of these figures by 0.6745 .

The weighted average of all values of $V$ given in column 4 of table 3 is 5.574 \pm 0.006 . In general, the values found for the individual groups deviate from this average by amounts within the range of accidental errors, so that with few doubtful exceptions the value $V=5.574 \mathrm{~km} / \mathrm{sec}$. can be considered a good approximation for the whole region. Using this value and all observed arrival times of $\overline{\mathrm{P}}$, corrected for the effect of focal depth, final origin times were determined for each shock. In 
four shocks they differ by 0.4 or 0.5 sec. from those determined by use of locally different velocities; in another five, the difference is 0.3 sec.; and in all others, 0.2 sec. or less. These final origin times are given in table 1; their standard error is listed

TABLE 4

Velocity of $\overline{\mathrm{P}}$, Assuming tue Origin Times in Table 1 which Are Calculated for $V=\mathbf{5 . 5 7 4}$ km/sec.; Standard ERroris (in Seconds) of The Origin Time $O$ and of INdividual Observed Times of Arrival $l$ of $\overline{\mathrm{P}}$, Again $A$ ssuming that $V=5.574 \mathrm{Km} / \mathrm{sec}$. and $O$ Are Correct ( $n=$ number of observations. For identification numbers of shocks see table 1.)

\begin{tabular}{|c|c|c|c|c|c|c|c|c|c|}
\hline \multirow{2}{*}{$\begin{array}{c}\text { Shock } \\
\text { no. }\end{array}$} & \multirow{2}{*}{$n$} & \multicolumn{2}{|c|}{ Standard error of } & \multirow{2}{*}{$V$} & \multirow{2}{*}{$\begin{array}{l}\text { Shock } \\
\text { no. }\end{array}$} & \multirow{2}{*}{$n$} & \multicolumn{2}{|c|}{ Standard error of } & \multirow{2}{*}{$V$} \\
\hline & & $o$ & $t$ & & & & 0 & $t$ & \\
\hline 1 & 6 & 0.2 & 0.4 & $\begin{array}{c}\mathrm{km} / \mathrm{sec} \\
\mathbf{5 . 5 9}\end{array}$ & 28 & 7 & 0.2 & 0.5 & $\begin{array}{c}\mathrm{km} / \mathrm{sec} . \\
5.59\end{array}$ \\
\hline 2 & 4 & 0.2 & 0.3 & 5.59 & 29 & 6 & 0.2 & 0.6 & 5.60 \\
\hline 3 & 8 & 0.1 & 0.2 & 5.57 & 30 & 9 & 0.1 & 0.4 & 5.57 \\
\hline 4 & 11 & 0.2 & 0.5 & 5.58 & 31 & 5 & 0.1 & 0.2 & 5.60 \\
\hline 5 & 9 & 0.1 & 0.4 & 5.59 & & & & & \\
\hline 6 & 6 & 0.2 & 0.3 & 5.60 & 32 & 7 & 0.2 & 0.4 & 5.58 \\
\hline 7 & 9 & 0.1 & 0.4 & 5.59 & 33 & 6 & 0.1 & 0.3 & 5.58 \\
\hline 8 & 5 & 0.2 & 0.4 & 5.55 & 35 & 5 & 0.1 & 0.2 & 5.57 \\
\hline 9 & 8 & 0.1 & 0.3 & 5.60 & & & & & \\
\hline 10 & 3 & 0.3 & 0.4 & 5.56 & 37 & $\begin{array}{l}8 \\
5\end{array}$ & $\begin{array}{l}0.1 \\
0.3\end{array}$ & $\begin{array}{l}0.4 \\
0.5\end{array}$ & $\begin{array}{l}5.57 \\
5.59\end{array}$ \\
\hline 11 & 6 & 0.2 & 0.4 & 5.57 & 38 & 5 & 0.2 & 0.4 & 5.58 \\
\hline 12 & 5 & 0.3 & 0.7 & 5.58 & 39 & 4 & 0.2 & 0.4 & 5.58 \\
\hline 13 & 6 & 0.1 & 0.1 & 5.57 & $\begin{array}{l}40 \\
41\end{array}$ & $\begin{array}{l}5 \\
2\end{array}$ & $\begin{array}{c}0.2 \\
(0.3)\end{array}$ & $\begin{array}{c}0.4 \\
(0.3)\end{array}$ & $\begin{array}{c}5.57 \\
(5.59)\end{array}$ \\
\hline 14 & 8 & 0.2 & 0.5 & 5.58 & 42 & 6 & 0.2 & 0.5 & 5.59 \\
\hline 15 & 6 & 0.2 & 0.5 & 5.57 & 43 & 5 & 0.1 & 0.3 & 5.57 \\
\hline 16 & 6 & 0.1 & 0.3 & 5.59 & 44 & 5 & 0.2 & 0.4 & 5.57 \\
\hline 17 & \multirow{2}{*}{10} & 0.1 & \multirow{2}{*}{0.4} & \multirow{2}{*}{5.57} & 40 & 4 & 0.2 & 0.3 & 5.58 \\
\hline & & & & & 46 & 7 & 0.2 & 0.4 & 5.56 \\
\hline 18 & \multirow{2}{*}{6} & \multirow{2}{*}{$\begin{array}{l}0.1 \\
0.1\end{array}$} & \multirow{2}{*}{$\begin{array}{l}0.3 \\
0.2\end{array}$} & \multirow{2}{*}{$\begin{array}{l}5.56 \\
5.57\end{array}$} & 47 & 4 & 0.2 & 0.3 & 5.56 \\
\hline 19 & & & & & & & & & \\
\hline 20 & 8 & 0.1 & 0.2 & 5.58 & 49 & 6 & 0.1 & 0.3 & $\begin{array}{l}0.08 \\
5.58\end{array}$ \\
\hline 21 & 6 & 0.1 & 0.3 & 5.59 & & & & & \\
\hline 22 & 8 & 0.1 & 0.2 & 5.57 & 50 & 9 & 0.2 & 0.5 & 5.58 \\
\hline 23 & 7 & 0.1 & 0.2 & 5.56 & & & & & \\
\hline 24 & 7 & 0.2 & 0.6 & 5.57 & & & & & \\
\hline 25 & 9 & 0.1 & 0.4 & 5.57 & & & & & \\
\hline 26 & 9 & 0.1 & 0.4 & 5.58 & & & & & \\
\hline 27 & 7 & 0.1 & 0.4 & 5.58 & & & & & \\
\hline
\end{tabular}

in the third column in table 4 , followed in the fourth column by the standard error for one observation of $\bar{P}$, if the adopted origin time and the velocity of $5.574 \mathrm{~km} / \mathrm{sec}$. is used. The standard error for one reading of $\bar{P}$ (including irregularities in drum speed and errors in time correction) has been found, in a previous investigation 
(Gutenberg, 1943a, p. 518), to be slightly less than 0.4 sec.; note that probable errors are given in that paper. It follows from column 4 in table 4 that the standard errors due to incorrect origin time, velocity of $\overline{\mathbf{P}}$, location of epicenters, and local idiosyncrasies at the stations, in general do not reach half a second.

The last column in table 4 exhibits the mean velocity of $\overline{\mathrm{P}}$ calculated from $\bar{P}-O$ for each individual shock, but omitting data from distances of less than $80 \mathrm{~km}$. The effect $\delta$ of an error $\tau$ in the observed travel time on the velocity $V$ is given by $\delta=\Delta \tau / t^{2} ;$ for $\overline{\mathrm{P}}$, approximately, $\delta=5.58 \tau / t$. The following errors $\delta$ result from $\tau=0.1$ sec.

$\begin{array}{ccccl}\Delta & 50 & 100 & 300 & \mathrm{~km} . \\ \delta & 0.06 & 0.03 & 0.01 & \mathrm{~km} / \mathrm{sec} .\end{array}$

On the other hand, the beginning of $\overline{\mathrm{P}}$ is less definite at distances beyond about 200 $\mathrm{km}$. Thus, the standard errors of $V$ depend partly on the distances for which observations of $\overline{\mathrm{P}}$ were available in a given shock.

The same values of $\bar{P}-O$ which were used for the calculation of $V$ for each individual shock (table 4) were combined in regional groups. The results, together with their standard errors and the numbers $n$ of observations, are given in the last three columns of table 3 . The difference in the two sets of values for $n$ in this table is due to the omission of data for distances of less than $80 \mathrm{~km}$. in the revision. Although the origin times in the revision are based on $V=5.574$, different values result from the calculation. Using all 277 observations for $\bar{P}-O$, the following values for the velocity $V$ of $\overline{\mathrm{P}}$ and its travel time $t$ were adopted:

$$
V=5.577 \pm 0.004 \mathrm{~km} / \mathrm{sec} . \quad t=0.1793 D
$$

$D$ is the hypocentral distance in $\mathrm{km} . D^{2}=h^{2}+\Delta^{2}$, where $h=$ focal depth, $\Delta=$ epicentral distance. The revised value of $V$ does not differ significantly from the weighted average of 5.574 of the first calculation and was used in all later calculations. The small standard error indicates only the consistency of the data; larger systematic errors due, for example, to the neglect of the sedimentary layers and the increase of velocity with depth are to be expected.

A few special instances of local idiosyncrasies are to be mentioned here. The lowest value of $V$ in the fourth column of table 3 belongs to shocks 32 to 35 with epicenters near $33^{\circ} 40^{\prime} \mathrm{N}, 117^{\circ} 32^{\prime} \mathrm{W}$ (region of the Elsinore fault, about $38 \mathrm{~km}$. south-southwest of Riverside). The rather low apparent velocity of $\overline{\mathrm{P}}$ seems to be mainly the effect of a relatively early arrival of $\overline{\mathrm{P}}$ at Riverside. This makes the time intervals between $\overline{\mathrm{P}}$ at Riverside and at more distant stations too long, and consequently $V$ too small. The revised value (table 3 , col. 7) with Riverside omitted (as its distance is less than $80 \mathrm{~km}$.) is close to normal. The average residuals for $\overline{\mathrm{P}}$ at Riverside, using the revised values of $O$ and $V$ for the four shocks, are $-0.4 \pm 0.1$ sec.; for both Pasadena and Mount Wilson the corresponding error is $-0.1 \pm 0.1$. Supposing that the observed times and the assumed values of the origin time are correct, the velocity from the source to Riverside would be about $5.9 \mathrm{~km} / \mathrm{sec}$. This may be compared with the velocity of about $6.0 \mathrm{~km} / \mathrm{sec}$. found by C. F. Richter from blasts near Riverside, and by H. O. Wood and C. F. Richter from blasts farther 
to the north (for summary and discussion of these results, see Gutenberg, 1943b). $\overline{\mathrm{S}}$ also arrives unusually early at Riverside in these four shocks. The average of all available residuals of $\overline{\mathrm{P}}$ at Riverside is about $-0.1 \pm 0.1$ sec.

In shocks 20 to 27 (Inglewood fault region) $\overline{\mathrm{P}}$ arrived too early at Pasadena by $0.23 \pm 0.12$ sec., while at Mount Wilson the time of arrival is too early by only $0.07 \pm 0.07$ sec. when the elevation of the stations is considered; for this correction see equation (1). Otherwise, there seem to be no systematic differences between the average velocity of $\overline{\mathrm{P}}$ to Pasadena and to Mount Wilson. (For details see Gutenberg, 1943a, table 7; for selected residuals of $\overline{\mathrm{P}}$ in individual instances see table 12 of that paper.) Taking larger areas, there is no evidence for systematic changes of $V$ within southern California.

\section{Travel Times of Py}

The phase Py corresponds to the waves which have their deepest point in the layer immediately below the granitic layer. In Europe the phase through a similar layer but with a different velocity is indicated by $P^{*}$ (see Gutenberg, 1943b).

Equation (1) gives the correction $-0.064 z$ for the elevation $z$ in $\mathrm{km}$. of the station. Consequently, 0.1 sec. was subtracted from all Py readings at Tinemaha, Haiwee, Mount Wilson, Palomar, and the stations of the Boulder City group. The effect of focal depth is practically the same for all distances.

The travel-time curve of Py for a given shock can be represented with sufficient approximation by $a+\Delta / V$, where $a$ is the "intercept time" of $\mathrm{Py}$, that is, the time after which Py seems to start at the epicenter, and $V$ the apparent velocity of Py. The average true velocity in the intermediate layer (average depth $h=R-r$, $R=$ radius of the earth) is given by $V r / R$.

The observed travel times of Py in groups of shocks similar to those used for $\bar{P}$ were subjected to the method of least squares, taking $a$ and $V$ as unknown quantities. As the value of $a$ depends on the focal depth as well as the thickness of the granitic layer, the results from the various shocks are expected to vary more than those for $\overline{\mathrm{P}}$. An increase in focal depth by $z \mathrm{~km}$. decreases $a$ by $0.07 z$ sec.; $a$ is decreased by the same amount if near the source the thickness of the granitic layer is $z$ $\mathrm{km}$. less than average. If, in addition, the shock occurred at a depth different from the usual, both corrections must be combined. While there is no indication of variable thickness of the granitic layer in southern California beyond the limits of error, the comparison of shocks in the same region (Gutenberg, 1943a) has shown that shock 7 had the same epicenter as shocks 4 to 6 , but originated about $5 \mathrm{~km}$. closer to the surface. For this reason, shock 7 was treated separately. In the final solution (table 5 , col. 9), as well as in table 6 , the value of $a$ for this shock is among the largest found, as was to be expected. There are, without doubt, instances of smaller variations in focal depth or of local differences in the thickness of the granitic layer, but for most shocks the amount of data and the range of distances available do not permit ascertainment of differences of the order of 10 per cent in focal depth or thickness of the layer by applying the method of least squares individually with two unknown quantities. It should also be noted that in the "revised" solution (table 5) the differences in the intercept times $a$ for the major groups (last four lines) are much smaller than in the original results (col. 5).

During the early stage of the investigation of Py it was not known which impulse 
corresponds to Py at epicentral distances of about $100 \mathrm{~km}$., as $\overline{\mathrm{P}}, \mathrm{Py}$, and $\mathrm{Pn}$ arrive within a very few seconds. For this reason, only records of shocks distant more than $120 \mathrm{~km}$. from the station were used in applying the method of least squares to readings of Py (cols. 2 to 7 of table 5). After the travel-time curve had been established by the method of least squares, there was no doubt that the records begin with Py,

TABLE 5

Velocity $V$ (km/sec.) of Py, Intercept Time $a$ (tn Seconds), Their Standard Errors, and NUMBER $n$ OF OBSERVATTONS USED

(For identification numbers of shocks see table 1. $\Delta=$ epicentral distance in $\mathrm{km}$. )

\begin{tabular}{|c|c|c|c|c|c|c|c|c|c|c|c|}
\hline \multirow{3}{*}{$\begin{array}{l}\text { Shock } \\
\text { no. }\end{array}$} & \multirow{3}{*}{$n$} & \multirow{3}{*}{$\begin{array}{l}\text { Range } \\
\text { of } \Delta\end{array}$} & \multirow{3}{*}{$V$} & \multirow{3}{*}{$a$} & \multicolumn{2}{|c|}{ Standard error } & \multicolumn{5}{|c|}{ Revised values of } \\
\hline & & & & & \multirow{2}{*}{$V$} & \multirow{2}{*}{$a$} & \multirow{2}{*}{$V$} & \multirow{2}{*}{$a$} & \multicolumn{2}{|c|}{ Standard error } & \multirow{2}{*}{$n$} \\
\hline & & & & & & & & & $V$ & $a$ & \\
\hline 1,2 & 20 & $129-545$ & 6.06 & 1.5 & 0.04 & 0.4 & 6.055 & 1.4 & 0.016 & 0.1 & 20 \\
\hline 3 & 8 & $311-534$ & 5.92 & 0.7 & 0.04 & 0.5 & 6.068 & 1.7 & 0.034 & 0.2 & 10 \\
\hline $4-6$ & 29 & $130-537$ & 6.14 & 1.6 & 0.04 & 0.3 & 6.023 & 0.7 & 0.013 & 0.1 & 30 \\
\hline 7 & 9 & $130-415$ & 6.01 & 1.4 & 0.04 & 0.1 & 6.050 & 1.7 & 0.019 & 0.1 & 9 \\
\hline 8,9 & \multirow{2}{*}{28} & \multirow{2}{*}{$130-411$} & \multirow{2}{*}{6.07} & \multirow{2}{*}{1.3} & \multirow{2}{*}{0.04} & \multirow{2}{*}{0.3} & $\{6.051$ & 1.0 & 0.020 & 0.1 & 14 \\
\hline $10-12$ & & & & & & & 6.041 & 1,2 & 0.013 & 0.1 & 16 \\
\hline $13-17$ & 20 & $133-544$ & 5.96 & 0.8 & 0.04 & 0.3 & 6.056 & 1.3 & 0.016 & 0.1 & 28 \\
\hline $20-27$ & 22 & $131-394$ & 6.00 & 1.0 & 0.04 & 0.3 & 6.048 & 1.2 & 0.016 & 0.1 & 28 \\
\hline $18-19$ & \multirow{2}{*}{19} & \multirow{2}{*}{$126-355$} & \multirow{2}{*}{6.09} & \multirow{2}{*}{1.3} & \multirow{2}{*}{0.07} & \multirow{2}{*}{0.5} & & 1.0 & & 0.3 & 4 \\
\hline $28-31$ & & & & & & & 6.036 & 0.8 & 0.020 & 0.2 & 17 \\
\hline $32-34$ & 6 & $214-385$ & 6.03 & 1.4 & 0.19 & 0.8 & 6.036 & 1.4 & 0.029 & 0.1 & 5 \\
\hline $36-45$ & 46 & $160-382$ & 6.00 & 1.1 & 0.02 & 0.1 & 6.053 & 1.3 & 0.009 & 0.1 & 56 \\
\hline 46,47 & 9 & $170-437$ & 6.06 & 1.0 & 0.04 & 0.4 & 6.053 & 1.0 & 0.019 & 0.1 & 13 \\
\hline $48-50$ & 21 & $123-546$ & 6.03 & 1.2 & 0.02 & 0.2 & 6.038 & 1.2 & 0.012 & 0.1 & 22 \\
\hline $1-7^{\text {a }}$ & 66 & $129-545$ & 6.08 & 1.5 & 0.03 & 0.3 & 6.046 & 1.16 & 0.009 & 0.08 & 69 \\
\hline $8-17^{b}$ & 48 & $130-544$ & 5.99 & 0.9 & 0.03 & 0.2 & 6.051 & 1.21 & 0.008 & 0.06 & 58 \\
\hline $18-50^{c}$ & 123 & $123-546$ & 6.03 & 1.1 & 0.02 & 0.1 & 6.047 & 1.21 & 0.006 & 0.04 & 145 \\
\hline $1-50$ & 237 & $123-546$ & 6.043 & 1.14 & 0.013 & 0.10 & 6.047 & 1.20 & 0.004 & 0.03 & 272 \\
\hline
\end{tabular}

a Northern Owens Valley.

b Remaining shocks north of the transverse mountain ranges.

- Shocks south of the transverse ranges.

at least at distances between 80 and $110 \mathrm{~km}$. (and in shocks 1 to 7 at least out to $170 \mathrm{~km}$.). Consequently, in table 6 and in the last five columns of table 5 additional data could be used; they are based on readings of the usually sharp beginnings of the records.

There is no indication of regional differences in the velocity of Py beyond the limits of error. The average of $6.043 \mathrm{~km} / \mathrm{sec}$. was used to calculate the intercept times $a$ for each shock. The results are given in table 6 , to which remarks apply similar to those made in connection with table 4 . The "standard error" for one observation of $\mathrm{Py}$ is found to be 0.47 sec., if all observations are combined. The last five 
columns of table 5 contain group averages found in the same way as the individual results of table 6 .

Taking all results into consideration, the following values have been adopted for the apparent velocity $V$, the intercept time $a$, and the travel time $t$ of $\mathrm{Py}(\Delta=$ epicentral distance in $\mathrm{km}$.) :

$$
V=6.047 \mathrm{~km} / \mathrm{sec} . \quad a=1.2 \mathrm{sec} . \quad t=(1.2+0.1654 \Delta) \mathrm{sec} .
$$

TABLE 6

Intercept Time $a$ of Py, Assuming $V=6.043 \mathrm{~km} /$ sec.; Velocity $V$, Assuming These Individual Values of $a$; Standard Errors of a and of the Observed Times $t$ of Argival of Py, Assuming That the Individual Values of $a$ and a Velocity $V=6.043 \mathrm{~km} / \mathrm{sec}$. Are CorRECT

( $n=$ number of observations. For identification numbers of shocks see table 1.)

\begin{tabular}{|c|c|c|c|c|c|c|c|c|c|c|c|}
\hline \multirow{2}{*}{$\begin{array}{c}\text { Shock } \\
\text { no. }\end{array}$} & \multirow{2}{*}{$n$} & \multirow{2}{*}{$a$} & \multicolumn{2}{|c|}{ Standard error } & \multirow{2}{*}{ V } & \multirow{2}{*}{$\begin{array}{l}\text { Shock } \\
\text { no. }\end{array}$} & \multirow{2}{*}{$n$} & \multirow{2}{*}{$a$} & \multicolumn{2}{|c|}{ Standard error } & \multirow{2}{*}{ Y } \\
\hline & & & $a$ & $t$ & & & & & $a$ & $t$ & \\
\hline 1 & 11 & $\begin{array}{l}\text { sec. } \\
1.5\end{array}$ & 0.1 & 0.4 & 6.06 & 28 & 3 & $\begin{array}{l}\text { sec. } \\
1.5\end{array}$ & 0.1 & 0.2 & 6.05 \\
\hline 2 & 9 & 1.1 & 0.2 & 0.6 & 6.06 & 29 & 4 & 1.6 & 0.2 & 0.3 & 6.07 \\
\hline 3 & 10 & 1.7 & 0.2 & 0.6 & 6.07 & 30 & 7 & 0.2 & 0,1 & 0.3 & 6.01 \\
\hline 4 & 10 & 0.8 & 0.2 & 0.6 & 6.02 & 31 & 3 & 0.7 & 0.3 & 0.4 & 6.02 \\
\hline 5 & 10 & 0.5 & 0.2 & 0.6 & 6.05 & & - & & & & \\
\hline 6 & 10 & 0.9 & 0.2 & 0.5 & 6.03 & 32 & 3 & 1.4 & 0.1 & 0.1 & 6.04 \\
\hline 7 & 9 & 1.7 & 0.1 & 0.3 & 6.05 & 33 & 1 & $\ldots$ & $\ldots$ & $\ldots$ & $\ldots$ \\
\hline 8 & 8 & 1.0 & 0.1 & 0.4 & 6.05 & 35 & $\overline{0}$ & & $\ldots$ & $\ldots$ & \\
\hline 9 & 6 & 1.0 & 0.2 & 0.4 & 6.04 & & & & & & \\
\hline 10 & 6 & 1.1 & 0.2 & 0.4 & 6.05 & $\begin{array}{l}36 \\
37\end{array}$ & $\begin{array}{l}9 \\
3\end{array}$ & $\begin{array}{l}1.2 \\
1.6\end{array}$ & $\begin{array}{l}0.1 \\
0.3\end{array}$ & $\begin{array}{l}0.2 \\
0.4\end{array}$ & $\begin{array}{l}6.04 \\
6.06\end{array}$ \\
\hline 11 & 6 & 1.6 & 0.2 & 0.3 & 6.05 & 38 & 7 & 1.5 & 0.1 & 0.3 & 6.06 \\
\hline 12 & 4 & 0.9 & 0.2 & 0.3 & 6.02 & 39 & 2 & (1.1) & $(0.2)$ & $(0.2)$ & $(6.06)$ \\
\hline & & -3 & & -1 & 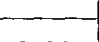 & 40 & 7 & 1.2 & 0.1 & 0.2 & 6.06 \\
\hline 13 & 4 & 1.0 & 0.2 & 0.4 & 6.06 & 41 & 8 & 1.2 & 0.1 & 0.3 & 6.04 \\
\hline 14 & 6 & 1.1 & 0.2 & 0.5 & 6.06 & 42 & 6 & 0.9 & 0.1 & 0.3 & 6.05 \\
\hline 15 & 4 & 1.0 & 0.4 & 0.6 & 6.04 & 43 & 5 & 1.4 & 0.2 & 0.5 & 6.08 \\
\hline 16 & 8 & 1.6 & 0.1 & 0.3 & 6.06 & 44 & 2 & $(1.5)$ & $(0.0)$ & $(0.0)$ & $(6.05)$ \\
\hline 17 & 6 & 1.5 & 0.2 & 0.4 & 6.05 & 45 & 7 & 1.5 & 0.2 & 0.5 & 6.06 \\
\hline 18 & 4 & 1.0 & 0.3 & 0.6 & 6.04 & 46 & 6 & 1.0 & 0.2 & 0.4 & 6.05 \\
\hline 19 & 1 & $\ldots$ & $\cdots$ & $\ldots$ & $\cdots$ & 47 & 7 & 1.1 & 0.2 & 0.4 & 6.05 \\
\hline 20 & 6 & 1.1 & 0.2 & 0.4 & 6.03 & 48 & 7 & 1.0 & 0.2 & 0.6 & 6.03 \\
\hline 21 & 1 & $\ldots$ & $\ldots$ & $\ldots$ & $\ldots$ & 49 & 8 & 1.3 & 0.1 & 0.3 & 6.05 \\
\hline 22 & 5 & 0.8 & 0.2 & 0.5 & 6.04 & 50 & 7 & 1.3 & 0.1 & 0.3 & 6.04 \\
\hline 23 & 2 & $(1.7)$ & $(0.3)$ & $(0.3)$ & $(6.02)$ & & & & & & \\
\hline 24 & 1 & $\ldots$ & $\ldots$ & $\ldots$ & $\ldots$ & & & & & & \\
\hline 25 & 5 & 1.7 & 0.2 & 0.4 & 6.06 & & & & & & \\
\hline 26 & 5 & 1.5 & 0.3 & 0.6 & 6.07 & & & & & & \\
\hline 27 & 5 & 1.4 & 0.2 & 0.4 & 6.05 & & & & & & \\
\hline
\end{tabular}




\section{Travel Times of Pn}

The phase Pn is produced by waves which have penetrated below the Mohorovičic discontinuity. The correction for the elevation $z$ in $\mathrm{km}$. of the station from equation (1) is $0.13 z$, which gives 0.2 sec. for Mount Wilson, Palomar, Haiwee, Lick, and Tinemaha, 0.1 sec. for the stations of the Boulder City group and for Tucson, and less than 0.05 sec. for the remaining stations used, all to be subtracted.

\section{TABLE 7}

Velocity $V$ (In km/sec.) of Pn, Intercept Time $a$ (In Seconds), Their Standard Errors, AND NUMBER $n$ OF OBSERVATIONS USED

(For identification numbers of shocks see table $1 . \Delta=$ epicentral distance in $\mathrm{km}$. )

\begin{tabular}{c|c|c|c|c|c|c|c|c|c|c|c}
\hline & & & & & \multicolumn{3}{|c|}{ Revised values of } \\
Shock \\
no.
\end{tabular}

Columns 2 to 7 of table 7 give the results of least squares solutions for the velocity $V$ of $\mathrm{Pn}$ and the intercept time $a$ for regional groups of shocks. Contrasting with $\mathrm{Py}$, the values of $a$ show differences definitely beyond the range of accidental errors. Therefore it was not possible to combine groups or all data for least squares solutions for $V$ and $a$. On the other hand, the resulting values for $V$ are the same within the limits of error. Theoretically a somewhat greater value for shocks numbered 1 to 7 is to be expected, considering the greater depth of the Mohorovičic layer near the source. This problem is discussed more in detail in connection with Sn. The weighted mean for $V$ is $8.064 \pm 0.11 \mathrm{~km} / \mathrm{sec} .(n=220)$. To determine $a$ for each shock (table 8), $0.124 \Delta$ was subtracted from the observed times; the numerical factor corresponds to $V=8.0645 \mathrm{~km} / \mathrm{sec}$. The differences in $a$ have been discussed previously (Gutenberg, 1943b). Results for the various regional groups based on the 
TABLE 8

Intercept Time $a$ of Pn, Assuming $1 / V=0.124$; Velocity $V$, Assuming These Individdal Values of $a$; Standard Errors of $a$ and of the Observed Trmes $t$ of Arrival of Pn, AssumING That THE INDIVIDUAL VALUES OF $a$ AND $1 / V=0.124$ ARE CoRrect

( $n=$ number of observations. For identification numbers of shockss see table 1.)

\begin{tabular}{|c|c|c|c|c|c|c|c|c|c|c|c|}
\hline \multirow{2}{*}{$\begin{array}{c}\text { Shock } \\
\text { no. }\end{array}$} & \multirow{2}{*}{$n$} & \multirow{2}{*}{$a$} & \multicolumn{2}{|c|}{ Standard error } & \multirow{2}{*}{$V$} & \multirow{2}{*}{$\begin{array}{c}\text { Shock } \\
\text { no. }\end{array}$} & \multirow{2}{*}{$n$} & \multirow{2}{*}{$a$} & \multicolumn{2}{|c|}{ Standard error } & \multirow{2}{*}{$V$} \\
\hline & & & $a$ & $t$ & & & & & $a$ & $t$ & \\
\hline 1 & 6 & $\begin{array}{l}\text { sec. } \\
9.0\end{array}$ & 0.1 & 0.2 & 8.06 & 28 & 6 & $\begin{array}{l}\text { sec. } \\
6.5\end{array}$ & 0.2 & 0.4 & 8.07 \\
\hline 2 & 5 & 8.9 & 0.2 & 0.4 & 8.07 & 29 & 4 & 6.0 & 0.2 & 0.4 & 8.04 \\
\hline 3 & 6 & 7.7 & 0.1 & 0.2 & 8.06 & 30 & 5 & 5.9 & 0.2 & 0.3 & 8.06 \\
\hline 4 & 9 & 9.0 & 0.1 & 0.3 & 8.06 & 31 & 4 & 5.9 & 0.1 & 0.2 & 8.07 \\
\hline 5 & 9 & 8.5 & 0.1 & 0.4 & 8.07 & & & & & & \\
\hline 6 & 9 & 8.8 & 0.1 & 0.4 & 8.07 & 32 & 7 & 7.1 & 0.1 & 0.4 & 8.07 \\
\hline 7 & 5 & 9.7 & 0.1 & 0.3 & 8.06 & 33 & 2 & $(6.8)$ & $(0.6)$ & $(0.6)$ & $(8.08)$ \\
\hline 8 & 6 & 6.4 & 0.1 & \multirow{2}{*}{$\begin{array}{l}0.3 \\
0.4\end{array}$} & \multirow{2}{*}{$\begin{array}{l}8.09 \\
8.07\end{array}$} & 35 & 0 & $\ldots$ & $\ldots$ & $\ldots$ & $\ldots$ \\
\hline 9 & 6 & 6.1 & 0.2 & & & & & & & & \\
\hline 10 & 6 & 7.3 & 0.1 & 0.3 & 8.07 & 37 & 5 & 7.4 & 0.1 & 0.2 & $\begin{array}{l}8.07 \\
8.06\end{array}$ \\
\hline 11 & 6 & 7.3 & 0.1 & 0.2 & 8.09 & 38 & 5 & 7.3 & 0.1 & 0.2 & 8.05 \\
\hline 12 & 5 & 5.8 & 0.4 & 0.7 & 8.00 & 39 & 4 & 7.2 & 0.1 & 0.2 & 8.05 \\
\hline & & & & & & 40 & 6 & 7.0 & 0.1 & 0.3 & 8.05 \\
\hline 13 & 4 & 6.5 & 0.2 & 0.3 & 8.07 & 41 & 4 & 7.3 & 0.1 & 0.1 & 8.07 \\
\hline 14 & 6 & 6.5 & 0.1 & 0.3 & 8.04 & 42 & 3 & 6.8 & 0.1 & 0.2 & 8.07 \\
\hline 15 & 5 & 6.2 & 0.1 & 0.2 & 8.05 & 43 & 2 & & . & $\ldots$ & $\ldots$ \\
\hline 16 & 9 & 6.4 & 0.1 & 0.3 & 8.05 & 44 & 3 & 7.2 & 0.1 & 0.2 & 8.04 \\
\hline \multirow{2}{*}{17} & \multirow{2}{*}{9} & \multirow{2}{*}{6.7} & \multirow{2}{*}{0.1} & \multirow{2}{*}{0.3} & \multirow{2}{*}{8.08} & 45 & 4 & 7.1 & 0.1 & 0.2 & 8.06 \\
\hline & & & & & & 46 & 6 & 6.6 & 0.2 & 0.5 & 8.08 \\
\hline 18 & 3 & 6.0 & 0.1 & 0.1 & 8.06 & 47 & 3 & 6.9 & 0.2 & 0.3 & 8.05 \\
\hline 19 & 4 & 5.9 & 0.2 & 0.3 & 8.09 & & & & & & \\
\hline 20 & 4 & 6.4 & 0.1 & 0.2 & 8.09 & 49 & $\begin{array}{l}0 \\
3\end{array}$ & $\begin{array}{l}5.9 \\
5.6\end{array}$ & $\begin{array}{l}0.1 \\
0.2\end{array}$ & $\begin{array}{l}0.2 \\
0.3\end{array}$ & $\begin{array}{l}8.05 \\
8.04\end{array}$ \\
\hline 21 & 1 & & & & $\ldots$ & & & & & & \\
\hline 22 & 5 & 6.5 & 0.1 & 0.2 & 8.04 & 50 & 11 & 6.0 & 0.1 & 0.3 & 8.06 \\
\hline 23 & 3 & 6.5 & 0.3 & 0.5 & 8.00 & & & & & & \\
\hline 24 & 1 & & & & & & & & & & \\
\hline 25 & 3 & 5.9 & 0.1 & 0.2 & 8.07 & & & & & & \\
\hline 26 & 3 & 6.3 & 0.3 & 0.5 & 8.08 & & & & & & \\
\hline 27 & 3 & 6.8 & 0.4 & 0.6 & 8.05 & & & & & & \\
\hline
\end{tabular}

material used in table 8 are given in the last five columns of table 7 . The average of all 236 values for $V$ from table 8 is $8.061 \pm 0.005 \mathrm{~km} / \mathrm{sec}$. Using this, the true velocity just below the Mohorovičić discontinuity (excluding the Sierra Nevada region) is found to be $8.02 \mathrm{~km} / \mathrm{sec}$.

The results for Pn are based on slightly more accurate readings than those for the other phases, as Pn forms the beginning of the seismogram whenever it is observed. On the other hand, the useful data begin at a larger distance, and in a number of shocks, for example the Inglewood fault group (shocks 20 to 27), a rather large 
number of the stations were too close to supply seismograms beginning with Pn. The variation in the depth of the Mohorovičic layer affects the arrival times of $\mathrm{Pn}$, depending not only on the locality of the source (value of $a$ ) but also on the station and the wave paths. All readings at Haiwee, Tinemaha, and the Berkeley group of stations were disregarded when there was a possibility that a path below the root of the Sierra Nevada may have delayed the arrival of Pn at these stations. The inclusion of such data was the main reason for lower velocities of Pn found previously in southern California shocks.

Data for shocks 3 and 7 were omitted in the first calculation (table 7 , left) since the residuals showed systematic "errors." Shock 7 is known to have originated at a shallower depth, as has been mentioned in the previous sections. The reason for the relatively small value of $a$ in shock 3 is not known; it may be a somewhat smaller depth locally of the Mohorovičic discontinuity, or a larger depth of focus at a point of greater thickness of the granitic layer.

The standard errors of the calculated velocity of $\mathrm{Pn}$ in table 8 are affected more by a given error of observation than the corresponding standard errors for $\overline{\mathrm{P}}$. The following values give the approximate effect of an error of 0.1 sec. in the observed arrival time of $\mathrm{Pn}$ :

$\begin{array}{lcccl}\text { Epicentral distance } & 100 & 200 & 300 & \mathrm{~km} . \\ \text { Error in calculated velocity of Pn } & 0.06 & 0.03 & 0.02 & \mathrm{~km} / \mathrm{sec} .\end{array}$

Thus far it has been assumed that the travel-time curve of Pn is exactly a straight line. The question of a possible curvature has been investigated by Jeffreys (1936). He pointed out that theoretically no term containing $\Delta^{2}$ is to be expected, and that for near-by shocks a term $-0.0025\left(\Delta^{\circ}-1^{\circ}\right)^{3}$ gives the smallest residuals. If $\Delta$ is expressed in kilometers, this gives approximately a term $-1.8\left(\frac{\Delta-111}{1000}\right)^{3}$. The best data for investigation of this effect seemed to be supplied by shocks 13 to 16 . There are observations available from various azimuths, the comparison of the shocks (Gutenberg, 1943a) promises as accurate epicenters as possible, and the range of distances seemed favorable (see table 7 ). The following equations for the travel times $t$ of $P$ n resulted:

a) Assuming a straight line:

$$
t=(6.0 \pm 0.2)+\frac{\Delta}{8.07 \pm 0.02}
$$

b) Including the term with $\Delta^{3}$ :

$$
t=(5.8 \pm 0.3)+\frac{\Delta}{8.21 \pm 0.08}+(2.6 \pm 1.2)\left(\frac{\Delta}{1000}\right)^{3}
$$

The cube term in $(b)$ is probably not significant; theoretically a minus sign is to be expected preceding this term. For further investigation of the problem, the residuals found in the calculation of the values in table 8 were grouped as a function of distance. The deviations $t$ (table 9) are in general within or close to their standard 
errors $f$. Only the value in the last line indicates a true difference; but all the six values used are based on arrival times at Tucson from Owens Valley shocks, and so this may be an effect of wave path. These six travel times were not used for tables 7 and 8 . Another interpretation is possible if one considers that the amplitudes of $\mathrm{Pn}$ at distances $\Delta$ beyond about $400 \mathrm{~km}$. decrease very rapidly with $\Delta$. From these amplitude observations alone the conclusion may be drawn that the velocity of longitudinal waves increases with depth immediately below the Mohorovičic discontinuity, but that the rate of increase decreases with depth; at a depth of about $80 \mathrm{~km}$. there may even be a (sudden or gradual) decrease of velocity with depth (see Gutenberg, 1943c). Thus, the residuals in table 9 may be explained by assuming that

\section{TABLE 9}

Average Residuals $t$ in Segconds for the Travel Time of Pn, Assuming $1 / V=0.124$ ANd $a$ as In TABLe 8 for Each Individual Shock

( $\Delta=$ epicentral distance in $\mathrm{km} . n=$ number of instances. $f=$ standard error of $t$.)

\begin{tabular}{|c|c|c|c|}
\hline Range of $\Delta$ & $n$ & $t$ & $f$ \\
\hline $117-150 \ldots \ldots$ & 22 & +0.04 & 0.06 \\
\hline $151-200 \ldots \ldots$ & 54 & +0.03 & 0.04 \\
\hline $201-250 \ldots \ldots$ & 22 & -0.03 & 0.07 \\
\hline $251-300 \ldots$ & 23 & 0.00 & 0.06 \\
\hline $301-350 \ldots$ & 23 & +0.12 & 0.07 \\
\hline $351-400 \ldots$ & 31 & +0.07 & 0.06 \\
\hline $401-500 \ldots$ & 24 & -0.10 & 0.06 \\
\hline $501-600$. & 26 & -0.08 & 0.07 \\
\hline $601-700$ & 8 & -0.20 & 0.14 \\
\hline $701-800$ & 2 & $(-0.15)$ & $(0.17)$ \\
\hline $801-849 \ldots$ & 6 & +0.02 & 0.12 \\
\hline $925-940 \ldots$ & 6 & +0.58 & 0.08 \\
\hline
\end{tabular}

we have to deal with a true refracted Pn wave only in the first part of table 9 , but with a diffracted wave at the end. This zone of diffracted $P n$ waves ends at an epicentral distance of about 1,600 km. Where it begins is not clear. The amplitudes of Pn (and Sn) decrease rather rapidly with distance beyond $200 \mathrm{~km}$., and the distance at which the energy of the diffracted wave begins to be larger than the energy of the refracted wave cannot be ascertained.

From table 9 it seems reasonable to combine the travel-time residuals $t$ up to a distance of $700 \mathrm{~km}$. It is of interest that Jeffreys (1936, p. 412) stated that in his analysis of travel times of $\mathrm{Pn}$ in sixteen Japanese earthquakes, data from distances beyond $8^{\circ}$ had to be "omitted as they may have a systematic error." The positive cube term found for shocks 13 to 16 is probably due to four observations with $\Delta>800 \mathrm{~km}$.; no data are available for distances $\Delta$ between 448 and $806 \mathrm{~km}$.

A least squares solution of the residuals $t$ in table 9 up to $\Delta=700 \mathrm{~km}$. was made by assuming a form $t=a+b \Delta^{\circ}+c\left(\Delta^{\circ}-1^{\circ}\right)^{3}$. In the last term $\left(\Delta^{\circ}-1^{\circ}\right)$ was used in agreement with Jeffreys' assumption; this corresponds to a subtraction of sections of the paths above the Mohorovičic discontinuity. In southern California 
shocks these sections are probably nearer to $1 / 2^{\circ}$, but the effect of the difference on the result is small. The values of $t$ in table 9 were found to be represented by

$$
t=(0.01 \pm 0.07)+(0.0111 \pm 0.0064) \Delta^{\circ}-(0.0023 \pm 0.0013)\left(\Delta^{\circ}-1^{\circ}\right)^{3}
$$

The numerical factor 0.0111 of $\Delta$ would decrease the value for the velocity by about $0.006 \mathrm{~km} / \mathrm{sec}$. The agreement of the numerical factor $(-0.0023)$ of $\left(\Delta^{\circ}-1^{\circ}\right)^{3}$ with the value -0.0025 of Jeffreys is partly coincidence, but indicates that by calculating this factor from various other groups of data it might be possible to establish its first significant figure beyond doubt.

Theoretically, the term with $\Delta^{3}$ is due to two main causes, the curvature of the earth's surface and the increase of velocity with depth. Assuming first that the velocity $V$ does not change with depth, the effect of the curvature of the earth's surface on travel time to a distance $\Delta$ in radians is given by $-R(\Delta-2 \sin 1 / 2 \Delta) / V$. ( $R=$ radius of the earth.) For small values of $\Delta$, neglecting terms of the fifth and higher powers in $\Delta$, this gives $-R \Delta^{3} / 24 V(\Delta$ in radians $)$, or about $-0.00018\left(\Delta^{\circ}-1^{\circ}\right)^{3}$ for $\mathrm{Pn}$. This is about -0.06 sec. for $\Delta=8^{\circ}$. Thus, the effect of curvature of the earth is too small to affect the observations used for tables 7 and 8 .

To investigate the effect of change in velocity with depth $z$, we assume $V=a+b z$ and neglect the effect of the curvature of the earth. The travel time $T$ for the path below the Mohorovičić discontinuity is given by

$$
T=2 \int_{0}^{h} \frac{d h}{V \cos i}=\frac{2}{b} \int_{\mathrm{V}_{0}}^{V} \frac{d V}{V \sqrt{1-(V / c)^{2}}}
$$

where $c=V_{0} / \sin i_{0}=V / \sin i$ and the Mohorovičic discontinuity is taken as reference level (subscript zero).

$T=\frac{2}{b}\left[\log \frac{c+\sqrt{c^{2}-V^{2}}}{V}\right]_{V}^{V_{0}}=\frac{2}{b}\left[\log \left(\frac{1}{\sin i}+\sqrt{\frac{1}{\sin ^{2} i}-1}\right)\right]_{\pi}^{i_{0}}=\frac{2}{b} \log \frac{1+\cos i_{0}}{\sin i_{0}}$

The distance $\Delta=\frac{2 a}{b} \cot i_{0}$ (neglecting the curvature of the earth).

$$
\begin{gathered}
\text { Introducing } \frac{1}{\sin i_{0}}=\sqrt{1+\cot ^{2} i_{0}}, \text { and } k=\cot i_{0}=\frac{b \Delta}{2 a} \\
T=\frac{2}{b} \log \left(k+\sqrt{1+k^{2}}\right)=\frac{2}{b}\left(k-\frac{k^{3}}{6}+\frac{3 k^{5}}{40}+\cdots\right)
\end{gathered}
$$

Neglecting terms with the fifth and higher powers of $\Delta$, the difference in travel time due to the assumed increase in velocity with depth is given for small epicentral distances $\Delta$ (in $\mathrm{km}$.) by

$$
-\frac{k^{3}}{3 b}=-\frac{b^{2} \Delta^{3}}{24 a^{3}} \text { sec. }
$$


Taking $a=8 \mathrm{~km} / \mathrm{sec}$, expressing $\Delta$ in degrees, and assuming an angular distance of $1^{\circ}$ for the paths in the upper layers, we find that for Pn the term with $\Delta^{3}$ is given by $-111 b^{2}\left(\dot{\Delta}^{\circ}-1^{\circ}\right)^{3}$. The value $-0.002\left(\Delta^{\circ}-1^{\circ}\right)^{3}$ would correspond to $b=0.004$, which is of the same order of magnitude as the value found from the investigation of amplitudes (Gutenberg, 1943c). However, the observed travel times at distances beyond about $7^{\circ}$, as well as the observed amplitudes, indicate that $b$ decreases with depth and even may become negative at a depth of 70 or $80 \mathrm{~km}$.

The following values for the travel times $t$ of $\mathrm{Pn}$ and its apparent velocity $V$ have been adopted:

$$
t=a+0.124 \Delta \quad V=8.06 \mathrm{~km} / \mathrm{sec} .
$$

$a$ depends on the region and varies between about 6 sec. for shocks in the coastal areas of southern California and at least 10 sec. for shocks under the Sierra Nevada.

\section{Travel Times of $\overline{\mathrm{S}}$}

As $\overline{\mathrm{S}}$ is the transverse wave corresponding to $\overline{\mathrm{P}}$, all remarks concerning $\overline{\mathrm{P}}$ refer correspondingly to $\overline{\mathrm{S}}$. If the fracture from which the waves start were a point, the travel-time curve for $\overline{\mathrm{S}}$ should be $D / V$ where $D=$ hypocentral distance, $V=$ velocity of $\overline{\mathrm{S}}$. However, the $\overline{\mathrm{S}}$ waves probably are propagated more slowly than the break along the fault, and consequently points closer to the end point than to the

TABLE 10

Velocity $V$ (Km/sec.) of $\overline{\mathrm{S}}$, Intercept Time $a$ (in Seconds), Their Standard Errors, and Numberis $n$ OF OBSERVATIONS USED

(For identification numbers of shocks see table 1. $\Delta=$ epicentral distance in $\mathrm{km}$. Columns 2 to 7 from $\bar{S}$-origin time, last two columns from $S-P$.)

\begin{tabular}{|c|c|c|c|c|c|c|c|c|}
\hline \multirow{2}{*}{ Shock no. } & \multirow{2}{*}{$n$} & \multirow{2}{*}{$\begin{array}{l}\text { Range } \\
\text { of } \stackrel{\Delta}{ }\end{array}$} & \multirow{2}{*}{$V$} & \multirow{2}{*}{$a$} & \multicolumn{2}{|c|}{ Standard error } & \multirow{2}{*}{$a$} & \multirow{2}{*}{$\begin{array}{l}\text { Standard } \\
\text { error } \\
\text { of } a\end{array}$} \\
\hline & & & & & $V$ & $a$ & & \\
\hline $1-7$. & 14 & $61-376$ & 3.28 & -0.1 & 0.02 & 0.5 & -0.2 & 0.5 \\
\hline $8,9,13-17 \ldots$ & 24 & $25-271$ & 3.26 & -0.8 & 0.02 & 0.3 & -0.4 & 0.1 \\
\hline $10-12 \ldots \ldots \ldots$ & 4 & $140-284$ & $\ldots$ & $\ldots$ & $\ldots$ & $\ldots$ & -0.5 & 0.8 \\
\hline $18,19,28-31$ & 22 & $15-323$ & 3.26 & -0.6 & 0.01 & 0.2 & -0.5 & 0.1 \\
\hline $20-27 \ldots$ & 22 & $31-155$ & 3.28 & +0.2 & 0.03 & 0.3 & -0.2 & 0.2 \\
\hline $32-35$. & 12 & $36-277$ & 3.21 & -1.1 & 0.02 & 0.3 & -0.6 & 0.2 \\
\hline $36-45$ & 25 & $97-272$ & 3.30 & -0.6 & 0.04 & 0.6 & -0.9 & 0.2 \\
\hline $46-50$ & 9 & $101-319$ & 3.24 & -1.0 & 0.03 & 0.6 & -0.9 & 0.3 \\
\hline $1-50$ & 128 & $15-376$ & 3.268 & -0.61 & 0.008 & 0.13 & -0.51 & 0.08 \\
\hline
\end{tabular}

point of beginning of faulting may receive the first $\overline{\mathrm{S}}$ waves from different points of the fault. As a consequence, the average apparent origin time of $\overline{\mathrm{S}}$ should be expected to be slightly earlier than that of $\bar{P}$, and the average travel time of $\bar{S}$ is given by $(a+D / V)$ where $a$ is negative. (For details see Gutenberg and Richter, 1943.) The apparent early start of $\overline{\mathrm{S}}$ in certain azimuths must result in larger residuals. Moreover, the time of arrival of all $S$ phases is usually less clearly defined than that of $\mathrm{P}$ phases. Consequently, the standard errors resulting from least squares solutions are larger for the $\mathrm{S}$ phases than for the $\mathrm{P}$ phases. While in the $\mathrm{P}$ phases probably the 
largest part of the standard "error" of a single observation (usually less than $1 / 2$ sec.) is due to the effect of incorrect location of the epicenters and to local idiosyncrasies near the stations, in the S phases probably incorrect identification of the beginning of the phases produces the main part of the standard errors of about 0.8 sec. for a single observation.

The following corrections $t$ for the effect of focal depth were applied to the observed travel times of $\overline{\mathrm{S}}$ :

$\begin{array}{ccccccccccccccr}\Delta & 15 & 20 & 25 & 30 & 40 & 50 & 60 & 70 & 80 & 100 & 120 & 150 & 200>300 \mathrm{~km} . \\ t & 2.6 & 2.1 & 1.8 & 1.5 & 1.2 & 0.9 & 0.8 & 0.7 & 0.6 & 0.5 & 0.4 & 0.3 & 0.2 & 0.1 \mathrm{sec} .\end{array}$

For least squares solutions the travel times of $\overline{\mathrm{S}}$ as well as observed time differences $\bar{S}-\bar{P}$ were used (table 10). The intercept time $a$ and its standard error in the last two columns of table 10 were found by supposing that $\bar{S}-\bar{P}=a+0.1275 D$. The numerical factor was taken from a least squares solution. The use of all 108 observed values of the time interval $d$ between $\overline{\mathrm{S}}$ and $\overline{\mathrm{P}}$ resulted in

$$
d=(-0.51 \pm 0.13)+(0.1275 \pm 0.0010) D
$$

where $D=$ hypocentral distance. The standard error for one observation of $\bar{S}$ as well as for one observed value of $\bar{S}-\bar{P}$ is about 0.7 sec.

If a velocity of $5.577 \mathrm{~km} / \mathrm{sec}$. is assumed for $\overline{\mathrm{P}}$, the velocity of $\overline{\mathrm{S}}$ resulting from equation (8) is $V=3.259 \mathrm{~km} /$ sec. Combining all results, equations (9) were taken as representative for the travel times $t$ of $\overline{\mathrm{S}}$ :

$$
t=-0.5+0.3066 D, \quad V=3.26 \mathrm{~km} / \mathrm{sec} .
$$

\section{Travel Times of Sy}

The phase Sy corresponds to Py. Originally the author (Gutenberg, 1932) had used the symbol Sm for this phase; $;$ the phase marked Sy in 1932 has not yet been studied in the present investigation. Equation (1) gives the correction -0.136z for the elevation $z$, which is about the same as for Pn. Results of the least squares solutions for the velocity and intercept time of Sy are given in table 11. The standard error for one observation corresponding to the results of the last line is 0.9 sec. The resulting travel time $t$ of Sy is given by

$$
t=2.1+0.274 \Delta \text { whence } V=3.65 \mathrm{~km} / \mathrm{sec} \text {. }
$$

As in the case of $\mathrm{Py}$, there is no clear indication that the intercept time $a$ or the velocity depend on the locality of the source or the station by an amount beyond the limits of error. In table 11, in most instances with deviations of $V$ and $a$ from the average exceeding the standard error, these deviations are in the same sense, either both positive or both negative. This is to be expected if the deviations are due to systematic incorrect identifications of the beginning of a phase for the usually few observations at longer distances.

"Note that on p. 32 of Gutenberg (1932) in the equations "Sy" and "Sm" are exchanged; Sy there corresponds to Sy in the present paper. 
TABLE 11

Veloctty $V$ (kM/sec.) of Sy, Intercept Time $a$ (Sec.), Thetr Standard Errors, and Numbers $n$ OF OBSERVATIONS USED

(For identification numbers of shocks see table $1 . \Delta=$ epicentral distance in $\mathrm{km}$. )

\begin{tabular}{|c|c|c|c|c|c|c|}
\hline \multirow{2}{*}{ Shock no. } & \multirow{2}{*}{$n$} & \multirow{2}{*}{ Range of $\Delta$} & \multirow{2}{*}{$V$} & \multirow{2}{*}{$a$} & \multicolumn{2}{|c|}{ Standard error } \\
\hline & & & & & $V$ & $a$ \\
\hline $1-7$. & 27 & $129-389$ & 3.66 & 2.4 & 0.02 & 0.5 \\
\hline $8,9,13-17$ & 23 & $105-278$ & 3.59 & 1.2 & 0.03 & 0.4 \\
\hline $10-12$ & 11 & $140-333$ & 3.65 & 2.6 & 0.06 & 0.6 \\
\hline $18,19,28-31$ & 17 & $105-355$ & 3.73 & 3.1 & 0.04 & 0.5 \\
\hline $20-27 \ldots$ & 12 & $103-367$ & 3.66 & 1.9 & 0.02 & 0.2 \\
\hline $36-45$ & 25 & $93-277$ & 3.57 & 1.9 & 0.04 & 0.4 \\
\hline $46-50 \ldots$ & 16 & $101-375$ & 3.61 & 1.2 & 0.04 & 0.6 \\
\hline $1-50$ & 131 & $93-389$ & 3.652 & 2.08 & 0.012 & 0.20 \\
\hline
\end{tabular}

\section{Travel Times of Sn}

Sn corresponds to Pn. It is the smallest of the three major S phases. While Pn marks the usually well-defined beginning in seismograms of short-period vertical Benioff instruments, $\mathrm{Sn}$ is superimposed on movement due to earlier phases (see fig. 1). Consequently, the number of useful observations is relatively small and the results are less accurate than those for Pn.

The correction for station elevation $z$ (in $\mathrm{km}$.) resulting from equation (1) is $-0.21 z$, which gives -0.4 sec. for Mount Wilson and Palomar, -0.3 sec. for Tinemaha, Haiwee, and Lick, -0.2 sec. for Boulder City and Tucson, -0.1 sec. for Pasadena, Riverside, Pierce Ferry, Boulder Dam, and Overton.

Table 12 contains the results of least squares solutions for the velocity $V$ and the intercept time $a$ for the various regional groups. The range of epicentral distances available from shocks 36 to 45 was too small for the determination of the velocity. As it was to be expected, from comparison with Pn, that shocks 3 and 7 would have a value of $a$ differing from the others, first tentative values of $a$ were determined for the whole group 1 to 7 by assuming $V=4.46$; for shock 3 , $a$ came out 0.7 sec. smaller, and for shock 7 , greater by 1.0 sec. than for the average of the others. Consequently, all readings of shock 3 were increased by 0.7 sec., and all of shock 7 decreased by 1.0 sec., before the method of least squares was applied to the whole group.

No attempt was made to combine all observations in one solution for $V$ and $a$. From columns 5 and 7 of table 12 it is evident that $a$ depends on the location of the source. The differences in $V$ are probably not significant. If 4.45 is assumed as the correct value, the largest deviations are only about $1 \frac{1}{2}$ times the standard error. It must be considered, besides, that the apparent velocities of $\mathrm{Pn}$ and $\mathrm{Sn}$ must be greater than the true velocity (aside from the effect of curvature of the earth's layers), if there is a "mountain root" near the source, and the Mohorovičic discontinuity is deeper under the hypocenter than under the station. The effect depends on the shape of the discontinuity; it would be equal to the effect known from "dip 
TABLE 12

Velocity $V$ (km/sec.) of Sn, Intercept Time $a$ (sec.), Theit Standard Errors, and Numbers $n$ OF OBSERVATIONS USED

$(t=$ standard error of one observation of Sn in sec., assuming that $1 / V=0.225 \mathrm{~km} / \mathrm{sec}$. and the value for $a$ in the eighth column are correct. For identification of shock numbers see table 1. $\Delta=$ epicentral distance in $\mathrm{km}$.)

\begin{tabular}{|c|c|c|c|c|c|c|c|c|c|}
\hline \multirow{3}{*}{ Shock no. } & \multirow{3}{*}{$n$} & \multirow{3}{*}{ Range of $\Delta$} & \multirow{3}{*}{$V$} & \multirow{3}{*}{$a$} & \multicolumn{2}{|c|}{ Standard error } & \multicolumn{3}{|c|}{ Supposing $1 / V=0.225$} \\
\hline & & & & & \multirow{2}{*}{$V$} & \multirow{2}{*}{$a$} & \multirow{2}{*}{$a$} & \multicolumn{2}{|c|}{ Standard error } \\
\hline & & & & & & & & $a$ & $t$ \\
\hline $1,2,4-6$ & 14 & $254-364)$ & & $(11.5)$ & & & $\int 12.6$ & 0.2 & 0.6 \\
\hline 3. & 4 & $264-356$ & 4.58 & $\{10.8\}$ & 0.09 & 0.5 & $\{11.8$ & 1.3 & 0.7 \\
\hline 7. & 3 & $259-311)$ & & $(12.5)$ & & & 13.6 & 0.7 & 0.5 \\
\hline $8,9,13-17 .$. & 24 & $130-457$ & 4.44 & 8.6 & 0.03 & 0.4 & 8.7 & 0.1 & 0.7 \\
\hline $11 \ldots \ldots \ldots$ & 3 & $143-212$ & $\ldots$ & $\ldots$ & $\ldots$ & $\ldots$ & 9.1 & 0.4 & 0.5 \\
\hline $18,19,28-31$ & 9 & $144-394$ & 4.46 & 9.0 & 0.07 & 0.8 & 8.8 & 0.2 & 0.7 \\
\hline $20-27$. & 11 & $135-611$ & 4.41 & 7.6 & 0.03 & 0.4 & 8.0 & 0.2 & 0.6 \\
\hline 32,33 . & 3 & $215-277$ & $\cdots$ & .. & & $\cdots$ & 9.1 & 0.7 & 0.9 \\
\hline $36-45$ & 15 & $162-170$ & & ... & & & 9.4 & 0.2 & 0.8 \\
\hline $46-50$ & 7 & 158-344 & 4.54 & 9.4 & 0.08 & 0.9 & 8.4 & 0.3 & 0.8 \\
\hline
\end{tabular}

shooting" in the seismic refraction method if the decrease in depth of the discontinuity is proportional to the epicentral distance, but would be similar to the effect of the focal depth on $\overline{\mathrm{P}}$ and $\overline{\mathrm{S}}$ if the mountain root does not extend far in the direction toward the station. On the other hand, it is quite reasonable to consider that beneath mountain roots the velocities of $\mathrm{Pn}$ and $\mathrm{Sn}$ are really greater than average.

TABLE 13

Intercept Times $a$ for Pn and Sn, Deviations $T$ from Average $A$ for the Coastal Area, and Resulting Deviation $d$ of the Thickness of "Mountain Root" (Below about 35 KM.) In the Epicentral Region

(For identification numbers of shocks see table 1)

\begin{tabular}{|c|c|c|c|c|c|c|c|}
\hline \multirow{2}{*}{ Shock no. } & \multicolumn{2}{|c|}{$a$ in seconds } & \multicolumn{2}{|c|}{$T$ see. } & \multicolumn{2}{|c|}{$d$ in $\mathrm{km}$. from } & \multirow{2}{*}{ Region of } \\
\hline & $\mathrm{Pn}$ & Sn & $\mathrm{Pn}_{\mathrm{n}}$ & Sn & $\mathrm{Pn}$ & Sn & \\
\hline $1,2,4-6$ & 8.8 & 12.6 & 2.6 & 4.1 & 24 & 26 & North of Owens Valley \\
\hline $10-12 \ldots$ & 6.9 & 9.1 & 0.7 & 0.6 & 6 & 4 & East of Mojave Desert \\
\hline $8,9,13-17$ & 6.2 & 8.7 & 0.0 & 0.2 & 0 & 1 & West of transverse ranges \\
\hline $18,19,28-31$. & 6.1 & 8.8 & -0.1 & 0.3 & -1 & 2 & West and east of Riverside \\
\hline $20-27$. & 6.5 & 8.0 & 0.3 & -0.5 & 3 & -3 & Inglewood fault \\
\hline 32,33 . & 7.0 & 9.1 & 0.8 & 0.6 & 7 & 4 & Elsinore \\
\hline $36-45$. & 7.2 & 9.4 & 1.0 & 0.9 & 9 & 6 & Little San Bernardino Mts. \\
\hline $46-50 \ldots \ldots \ldots$ & 6.0 & 8.4 & -0.2 & -0.1 & -2 & -1 & Terwilliger, Imperial Valley \\
\hline A... & 6.2 & 8.5 & & & & & \\
\hline
\end{tabular}


Supposing that the velocity increases with depth $z$ (in $\mathrm{km}$.) by $0.004 z$ for Pn and by $0.002 z$ for $\mathrm{Sn}$, and that the Mohorovičić discontinuity is $25 \mathrm{~km}$. deeper under the northern Owens Valley than in the coastal areas of southern California (see table 13), differences in velocity of $P n$ by $0.1 \mathrm{~km} /$ sec. and by 0.05 for $\mathrm{Sn}$ would result from the increase of the elastic constants with confining pressure (Gutenberg, 1943c). However, a higher velocity of $\mathrm{Pn}$ and $\mathrm{Sn}$ in the epicentral region of a shock does not change noticeably the resulting "apparent" velocity, if only a small fraction of the wave path is in the area of increased velocity.

In the region of the shocks numbered 1 to 7 the calculated apparent velocity of Pn does not differ noticeably from the average (table 7). Therefore it seems likely that most of the deviation of $V$ from the average for $\mathrm{Sn}$ in these shocks (table 12) is due to accidental errors.

In spite of all irregularities, it was finally deemed reasonable to assume that the velocity of $\mathrm{Pn}$ is the same everywhere in southern California. As representative value for normal conditions, $1 / V=0.225 \mathrm{sec} / \mathrm{km}$. (or $V=4.444$ ) was adopted for the calculation of the last three columns of table 12. The regional variations of $a$ are similar for Pn and Sn (table 13). This supports the assumption that the order of magnitude of the difference is correct. They can be used to calculate the approximate deviation $d$ of the lower boundary of the mountain root below the corresponding level in the coastal area in southern California (or the difference in depth of Mohorovičić discontinuity). From $T=a-A(a=$ individual intercept time, $A=$ average of $a$ in coastal area) we find

$$
d=\frac{T}{\sqrt{\frac{1}{v^{2}}-\frac{1}{w^{2}}}}
$$

where $v=$ velocity in the intermediate layer, $w=$ velocity below the discontinuity. This gives approximately

$$
\text { for } \mathrm{P} \quad d=9.1 T \quad \text { and for } \mathrm{S} \quad d=6.4 T
$$

For results, see columns 6 and 7 of table 13 .

The following values for the travel time $t$ and the apparent velocity $V$ of $\mathrm{Sn}$ finally were taken as representative of the observations:

$$
t=a+0.225 \Delta \quad V=4.45 \mathrm{~km} / \mathrm{sec} .
$$

where $a$ depends on the region (see col. 3 of table 13).

\section{Summary}

Study of arrival times of the principal phases in fifty of the larger and better recorded earthquakes in southern California resulted in the following travel times $t$ (seconds) and apparent velocities $V(\mathrm{~km} / \mathrm{sec}$.$) :$

$$
\begin{array}{lll}
\overline{\mathrm{P}} & t=0.1793 D & V=5.577 \\
\mathrm{Py} & t=1.2+0.1654 \Delta & V=6.047 \\
\text { Pn } \quad t=x+0.124 \Delta & V=8.06
\end{array}
$$

$$
\begin{array}{lll}
\overline{\mathrm{S}} & t=-0.5+0.3066 D & V=3.26 \\
\text { Sy } t=2.1+0.274 \Delta & V=3.65 \\
\text { Sn } t=y+0.225 \Delta & V=4.45
\end{array}
$$


$\Delta=$ epicentral distance, $D^{2}=\Delta^{2}+h^{2}, h=$ focal depth. $x$ and $y$ depend on the region; the following are characteristic values

$\begin{array}{ccccc}\text { Coastal areas, } & \begin{array}{c}\text { Mountain areas, } \\ \text { low valleys } \\ \text { southeastern Calif. }\end{array} & \begin{array}{c}\text { Northern } \\ \text { Owens Valley }\end{array} & \begin{array}{c}\text { Sierra } \\ \text { Nevada }\end{array} \\ x & 6 & 7 & 9 & 10 \pm \text { sec. } \\ y & 81 / 2 & 91 / 2 & 121 / 2 & 14 \pm \text { sec. }\end{array}$

The average true velocities of Py and Sy are about one-third of one per cent, those of Pn and Sn about one-half of one per cent, smaller than the corresponding apparent velocities. In the uppermost $50 \mathrm{~km}$. the velocity increases with depth. The order of magnitude of this increase is roughly 1 per cent per 10 kilometers, but larger in the uppermost one or two kilometers. It can be found from a study of amplitudes (Gutenberg, 1943c); its effect on the travel times exceeds the limits of error by too small an amount to be ascertained beyond doubt from the data of the present paper. The curvature of the earth can be disregarded within the range of distances used (in general not exceeding $800 \mathrm{~km}$.). The effect of "mountain roots" on the travel times of Pn and Sn is investigated.

Reproduction of travel-time curves and recalculation of the thickness of the various layers must wait until a study of other (especially reflected) recorded phases now under way is finished. Preliminary values are $18 \mathrm{~km}$. for the thickness of the granitic layer with small local variations, and about $35 \mathrm{~km}$. for the total of the crustal layers in the coastal areas of southern California with an increase inland approaching twice that amount under the Sierra Nevada.

California Institute of Technology

Pasadena, California

[Balch Graduate School of the Geological Sciences, Contribution No. 358.]

\section{References}

Gutenberg, B.

1932. "Travel-time Curves at Small Distances and Wave Velocities in Southern California," Gerlands Beitr. z. Geophysik, 35:6-50.

1943a. "Earthquakes and Structure in Southern California," Bull. Geol. Soc. Am., 54:499-526.

1943b. "Seismological Evidence for Roots of Mountains," Bull. Geol. Soc. Am., 54:473-498.

1943c. "Variations in Physical Properties within the Earth's Crustal Layers." Not yet published. Abstract in Trans. Am. Geophys. Union, 1943: 281-282.

Gutenberg, B., and C. F. Richter

1943. "Apparent Origin Time of $\overline{\mathbf{S}}, "$ Bull. Seism. Soc. Am., 33:269-279.

JEFTREYS, H.

1936. "The Structure of the Earth Down to the $20^{\circ}$ Discontinuity," Mon. Not. Roy. Astron. Soc., Geophys. Suppl., 3:401-422. 